\title{
Foundational Grounding and the Argument From Contingency*
}

\author{
Kenneth L. Pearce \\ Trinity College Dublin
}

September 12, 2016

\begin{abstract}
The argument from contingency for the existence of God is best understood as a request for an explanation of the total sequence of causes and effects in the universe ('History' for short). Many puzzles about how there could be such an explanation arise from the assumption that God is being introduced as one more cause prepended to the sequence of causes that (allegedly) needed explaining. In response to this difficulty, I defend three theses. First, I argue that, if the argument from contingency is to succeed, the explanation of History in terms of God must not be a causal explanation. Second, I argue that a particular hypothesis about God's relation to History - that God is what I call the foundational ground of History - is intelligible and explanatory. Third and finally, I argue that the explanatory advantages of this hypothesis cannot be had within the confines of naturalism.
\end{abstract}

Unlike the Kalam cosmological argument for the existence of God (Craig 1979), the cosmological argument from contingency is not a request for a cause of the origination of the universe. Rather, it is a request for an explanation of the total sequence of causes and effects in the universe. (Call this sequence 'History'.) Many philosophers have, however, been puzzled as to how there could be such an explanation and, especially, as to how God could serve as such an explanation, as the cosmological arguer desires. This puzzlement stems from the fact that proponents of the argument from contingency are often seen as introducing God in just the same way as the proponents of the Kalam argument do, that is, as one more 'billiard ball' prepended to the causal sequence studied by natural science. If this is the case, then no progress has been made. We have merely added one more cause to the sequence of causes that (allegedly) needed explaining.

${ }^{*}$ Forthcoming in Oxford Studies in Philosophy of Religion. 
In response to this difficulty, I defend three theses. First, I argue that, if the argument from contingency is to succeed, the explanation of History in terms of God must not be a causal explanation. Second, I argue that a particular hypothesis about God's relation to History - that God is what I call the foundational ground of History - is intelligible and explanatory. Third and finally, I argue that the explanatory advantages of this hypothesis cannot be had within the confines of naturalism.

\section{God is Not the Cause of History}

Leibniz presents the argument from contingency as follows:

A sufficient reason for existence cannot be found merely in any one individual thing or even in the whole aggregate and series of things. Let us imagine the book on the Elements of Geometry to have been eternal, one copy always being made from another; then it is clear that though we can give a reason for the present book based on the preceding book from which it was copied, we can never arrive at a complete reason, no matter how many books we may assume in the past, for one can always wonder why such books should have existed at all times; why there should be books at all, and why they should be written in this way. What is true of books is true also of the different states of the world ... No matter how far we may have gone back to earlier states, therefore, we will never discover in them a full reason why there should be a world at all, and why it should be such as it is.

Even if we should imagine the world to be eternal, therefore, the reason for it would clearly have to be sought elsewhere ... For even though there be no cause for eternal things, there must yet be understood to be a reason for them ... These considerations show clearly that we cannot escape an ultimate extramundane reason for things, or God, even by assuming the eternity of the world (Leibniz [1697] 1969, 486-487).

In another presentation of the argument, Leibniz asserts that this 'extramundane reason' (God) must be "a necessary being bearing the reason for its existence within itself; otherwise we would not yet have a reason with which to stop" (Leibniz [1714] 1969, §8).

Leibniz is here searching for an explanation of "the whole aggregate and series of things." From the way his argument progresses, it seems that what he has in mind is a complex event, which we might call the Causal History of the Universe ('History' for short). This is the event composed of all the events of the form $x$ causes $y$. Leibniz assumes that each state of the universe can be explained by specifying its physical causes, which are to be found in earlier states of the universe, but, he says, there must be a reason why this total series 
is as it is and not otherwise and that reason cannot possibly be found inside the series.

I here assume that the complex event History exists and is the sort of thing that stands in need of explanation. ${ }^{1}$ Given this assumption, the argument from contingency could function as a proof of the existence of God if we could establish that History must have an explanation (presumably by establishing a sufficiently strong Principle of Sufficient Reason) and that all possible explanations of History rely on some form of theism. Here I interpret the argument more modestly as aiming merely to show that theism has an advantage over its chief rival, naturalism, with respect to explanatory comprehensiveness. By 'naturalism' I here mean the view that any metaphysics that goes beyond natural science ought to be rejected. To show that theism has the advantage over naturalism with respect to explanatory comprehensiveness, the cosmological arguer need only show that there exists at least one theistic explanation of History while there can be no naturalistic explanation of History. ${ }^{2}$

Recent presentations of the argument have often held that the way to do this is to introduce God (or God's free choice) as the cause of the origination of the universe. ${ }^{3}$ Causal versions of the argument from contingency turn on a particular view about the causal structure of reality: they say that there is a non-physical (divine) cause that precedes all physical causes, and that this generates an explanatory advantage for the theist. This argument fails, as Graham Oppy convincingly argues, because whatever causal structure for the universe is supposed by the theist can be replicated by the naturalist (Oppy 2013). The naturalistic philosopher has wide latitude here, since there are many different live models in physical cosmology which exhibit different causal structures. To prefer one live physical hypothesis over another is not to go beyond natural science in the way the naturalist finds objectionable. Thus if the free action of God is supposed to be the indeterministic action of a necessary being, the naturalist is free to propose that the universe had an initial state which was itself necessary and indeterministically caused the organized cosmos we experience. If the theist introduces an infinite causal chain (perhaps of divine thoughts), the naturalist can introduce an infinite chain of earlier states of the universe (or parent universes). Finally, if the theist proposes an initial contingent being (rejecting divine necessity), the naturalist is free to accept an initial contingent state of the universe. Whatever advantage the theistic model is supposed to have will also be had by at least some physical models and therefore (at least

1. The assumption that History exists can be dispensed with if, as Dasgupta 2014a argues, the grounding relation is irreducibly plural, for then we could argue that the causal events are plurally grounded in God's creative activity.

2. Analogous arguments can be made using a Big Conjunctive Contingent Fact, or the set or mereological sum of all concrete contingent beings, or any number of other (alleged) entities in place of History.

3. See, e.g., Koons 1997; 2008, §2; Pruss 2004, 170-171; 2011, 220; O'Connor 2008, 2013. Admittedly, it is unclear whether these authors intend their ascriptions of causality to God literally and univocally, but if the relation is not literally and univocally causation, then an account of the nature of that relation is owed, and none of these authors has provided such an account. I will undertake this task in the next section. 
as long as these models continue to be live options within physics) can be had within the confines of naturalism.

Nor does it help to point out that God is supposed to be a necessary being, and no physical entity is necessary, for God's alleged necessity must be either transparent or opaque. (That is, either we can see why God is necessary or we can't.) If the argument depends on transparent necessity, then the argument from contingency can be introduced only after a successful ontological argument (see Kant [1781] 1998, A606/B634-A612/B640). ${ }^{4}$ If the argument from contingency is to stand alone, then God's necessity must be opaque. That is, the argument should give us reason to believe that a necessary being (God) exists, although we do not (yet) understand why the existence of this being is necessary. ${ }^{5}$ However, if this is the theist's position, then the naturalist is free to claim that some relevant part of physical reality possesses opaque necessity. ${ }^{6}$

If the argument from contingency is to succeed, we must take more seriously Leibniz's statement that the argument introduces an 'extramundane reason' for History. By introducing God as one more 'billiard ball' prepended to History, causal versions of the argument make God too 'mundane' to explain anything the naturalist can't. Rather than positing a particular causal structure for the universe and giving God a privileged role in that structure, the argument from contingency must instead posit God as a non-causal explanation of why reality has the causal structure it does. Only in this way can theism gain an explanatory advantage over naturalism.

\section{God is the Foundational Ground of History}

There can be no causal explanation of History, for History is the sum of all the causal events. Accordingly, an event of the form $x$ 's causing History would itself be part of History and so could not, on pain of circularity, explain History. Of course, the theist is at liberty to identify another complex event, call it 'History-', which includes all of History except God's causal activity (cf. Oppy 2009, 35). This, however, would be a mistake since the naturalist is equally entitled to posit a cause of History-. If the argument from contingency is to work, we must demand an explanation of History as a whole, and this means demanding a non-causal explanation. Such an explanation can be provided by positing God as the foundational ground of History.

In classical philosophical theology, the term for what I am calling 'foundational grounding' is 'primary causation. ${ }^{7} \mathrm{I}$ have chosen instead to use the term 'foundational grounding' because I am arguing that the (so-called) primary causation relation is not a causal relation (except perhaps in an analogical sense). ${ }^{8}$

4. For discussion see Forgie 1995; Vallicella 2000; Smith 2003; Proops 2014.

5. See Adams 1983; Forgie 1995; Gale and Pruss 1999, 462, 470; O'Connor 2008, 70-71; $2013, \S 2$.

6. According to Joseph K. Campbell, this dilemma plays a crucial role in Hume's criticism of the argument from contingency (Campbell 1996).

7. Latin prima causa. See, e.g., Aquinas Summa Theologica, Iq19a5r2 and Iq19a6r3.

8. My claim that (so-called) primary causation is not a causal relation is not an interpretive 
The Greek word ' $\alpha i t i \alpha$ ' and its Latin translation 'causa' can refer to any answer to a 'why' question (Hocutt 1974). These terms are therefore much broader than 'cause' in contemporary English. The term 'primary causation' is misleading, since we ought not to assimilate the kind of ultimate explanation provided by God to ordinary causal explanation.

In place of the misnomer 'primary causation,' I have chosen the label 'foundational grounding.' By 'grounding' I mean the relation, or genus of relations, that obtains between more fundamental and less fundamental entities and makes metaphysical explanations of the less fundamental entities (or the facts about them) in terms of the more fundamental entities possible. ${ }^{9}$ Thus, for instance, physicalists about the mind are to be understood as claiming that the mental is grounded in the physical.

I call God's grounding of History foundational because the grounding relations generate a metaphysical hierarchy, with the less fundamental things 'built on' the more fundamental things, so to speak (see, e.g., Schaffer 2009a; 2012, $\S 4.3$; Fine 2012, 44-45, 51). If God grounds History as a whole, God's grounding must be somehow foundational in this hierarchy.

The aim of this section is to defend my claim that the hypothesis God is the foundational ground of History is intelligible and is explanatory of History.

\subsection{Foundational Grounding is Intelligible}

In order to show that foundational grounding is intelligible, I here construct a particular model of foundational grounding. My model is meant to be consistent with classical theistic commitments. In particular, it aims to preserve traditional divine attributes as well as the following three claims: (1) contrary to pantheism, the world is numerically distinct from God; (2) contrary to panentheism, the dependence of the world on God is asymmetric (God does not depend on the world); and (3) contrary to necessitarianism or emanationism, God was free to create a different world or none at all. Additionally, my model does not posit any divine causality. ${ }^{10}$ I will not be defending the superiority of my model over other (classical or non-classical) theistic models. My aim in presenting this model is only to show that there exists at least one theistic hypothesis capable of explaining History.

My model has three stages, each involving a different grounding relation: (1) God performs an act of will. (2) This act of will constitutes History. (3) His-

claim about Aquinas or any other classical philosophical theologian (though I do think the interpretive claim is plausible). It is, rather, a claim about how the classical theist ought to understand the relation she takes to obtain between God and creation.

9. I am thus using 'grounding' more broadly than some theorists (e.g., Audi 2012, 105). In my usage, the constitution relation between statue and clay, for instance, is a type of grounding and if parts are more fundamental than wholes then so is composition. Karen Bennett refers to the members of this genus as 'building relations' (Bennett 2011).

10. The model is not inconsistent with divine causality; it simply does not make use of divine causality in explaining History. It will turn out that within this model God could exercise causality (in a literal and univocal sense) only by entering into History as a character in the story. On the prospects for this kind of move, see Lebens, forthcoming. 
tory is the narrative ground of particular created things like you and me. All three relations admit of non-theological examples. The first is the relation of an agent to her action. The second is the relation of a statue to its material. The third is the relation whereby fictional objects depend on fictional narratives and dream objects depend on dreams. As is to be expected, there are a number of peculiarities involved in the present application of these relations.

The performance relation is a type of grounding relation. An agent may perhaps be the (an) efficient cause of her action, but this is not like causing a boulder to roll down a hill, where one merely sets it going. A dance, for instance, continues to exist so long as the agent continues performing it. The agent sustains the dance in being by bearing the performance relation to the dance. This performance relation is not itself causal. In the same way, God sustains God's act in being by performing it.

Constitution is also a grounding relation: the statue exists because the lump exists and is so arranged. According to the model, this relation likewise obtains between God's act and History.

There are two main difficulties for this claim: first, in the paradigm cases the constitution relation is a relation between objects, but History and God's act are both events. ${ }^{11}$ Second, in typical cases of 'bringing about' the state of affairs brought about is something over and above the act of bringing about, but a constituted object is nothing over and above the constituting object.

In response to the first objection, it should be noted that there are cases where it is perfectly natural to say that one event constitutes another. For instance, the discovery of the Higgs boson was constituted by the recording of certain data in certain machines. Similarly, Jones's raising her hand might constitute Jones's voting (cf. Baker 2007, 111-119). The notion that God's act could constitute an event like History is not one that we should balk at. ${ }^{12}$

A way of putting the second objection is to observe that God's act of creation is supposed to be an exercise of omnipotent power. Now, in typical cases of the exercise of power, the agent's act of will produces effects that are something over and above that act: if Hercules is a powerful lifter of stones, then his willing to lift a stone results in something over and above the willing itself, namely, the stone's being lifted. However, when a lump constitutes a statue we say that the statue is nothing over and above the lump. A supporter of univocal divine causality might argue that if the product of God's act is never anything over and above the act itself then God is not powerful.

This, however, gets things precisely the wrong way around. The fact that the stone's being lifted is something over and above Hercules' act is what gives rise to the possibility that Hercules' will might be thwarted. This is not the case with God. ${ }^{13}$ As Nicolas Malebranche put it: "it suffices that [God] wills in order that a thing be, because it is a contradiction that He should will and that what

11. I thank Sandra Visser for this objection.

12. On constitution relations among events/activities, see van Inwagen 1990, 82-83; Pereboom 2011, 139-141.

13. For further examination of the difference between limited creaturely powers and the Infinite Power of God, see Pearce, forthcoming(b). 
He wills should not happen" (Malebranche [1674-1675] 1997, 450; cf. Bonhoeffer 1997, 42-43). It is the fact that the fulfillment of God's will is nothing over and above God's willing that makes God's will perfectly efficacious.

Alexander Pruss and I have argued that perfect efficacy of will is one component of omnipotence (Pearce and Pruss 2012). (The other component is perfect freedom.) We analyze perfect efficacy of will as follows (405):

$x$ has perfect efficacy of will if and only if $(p) \square((x$ wills $p) \square \rightarrow(x$ intentionally brings about $p$ ))

In this definition, ' $\square \rightarrow$ ' symbolizes the subjunctive conditional and it is stipulated that all of the relevant conditionals, including those that are counterpossibles, must be non-trivially true.

A constitution relation, such as the one at issue here, can give rise to nontrivial counterpossibles of the sort required by this analysis. For comparison, consider the following counterpossible conditional:

(Michelangelo, having artistic intentions, shapes a block of marble into a round square) $\square \rightarrow$ (that marble constitutes a round square statue)

This conditional is true because of certain metaphysical laws which arise from the nature of the constitution relation that obtains between a statue and its material. The law is something like, whenever a shape is imposed on some material with artistic intentions, that material thereby comes to constitute a statue. This law supports subjunctive conditionals, including counterpossibles. ${ }^{14}$ In the same way, the constitution relation between History and God's act of will gives rise to a metaphysical law that supports subjunctive conditionals, including counterpossibles such as:

(1) (God wills that a certain particle be both charged and neutral) $\square \rightarrow$ (God intentionally brings it about that that particle is both charged and neutral)

and

(2) (God wills that every sentient being suffers excruciating pain during every moment of its existence) $\square \rightarrow$ (God intentionally brings it about that every sentient being suffers excruciating pain during every moment of its existence)

The antecedent of (1) is impossible due to God's essential perfect rationality; the antecedent of (2) is impossible due to God's essential moral perfection (see Pearce and Pruss 2012, 411-412). Each of these counterpossibles is, however, non-trivially true because of the constitution relation that obtains between God

14. This sort of 'covering law' approach to (at least some) counterpossibles is defended in Pearce 2016. 
and History. ${ }^{15}$ The hypothesis that God's act of will constitutes History is thus a help, rather than a hindrance, to a satisfying account of God's power. ${ }^{16}$

The final question to be addressed is the status of created beings like you and me. History, according to this model, is the narrative ground of such beings.

When one dreams of Paris, one's dream is about Paris - the actual Paris, in the world, and not a shadowy dream Paris. This may be the case even if one dreams that Paris is in England (or Narnia) and is populated only by purple mice. However, one also sometimes dreams of persons, things, or events that do not exist outside one's dream. These items are made to exist by the dreamer's activity of dreaming. The existence of such an object is grounded in the dream.

The case is similar for fictional objects. Sherlock Holmes, for instance, exists because there are stories about him. His existence is grounded in those stories (cf. Thomasson 1999, 35-38, et passim; Kripke 2013, 72-74).

According to the model I am proposing, this relation of narrative grounding also obtains between created objects and History. This need not imply that History is literally a narrative, but it does imply that History is similar to a narrative. This does not seem especially problematic, since a narrativei.e., that which is narrated - is a (possibly fictitious) complex event. Whether regarding History as the narrative ground of created objects requires History to have other features typically possessed by narratives (for instance, having some meaning or significance, having certain themes, having literary structure) is not a question I will attempt to answer here, though I note that the view that History does have these features will likely be attractive to many theists. ${ }^{17}$

The most important objection to this proposal is that it empties created objects of their reality and causal efficacy, making God the only true reality and the only true cause. In a dream the dreamer is the one who really exists and really (though usually involuntarily) makes the things in the dream happen. The objects in the dream do not really exist (they are only dream objects) and do not really cause anything (they only dream-cause dream-events).

The classical theistic tradition has held that these results are in a sense acceptable: created objects, the tradition holds, possess diminished reality as compared to God, and the 'secondary causation' exercised by created objects is a less ultimate form of 'making it the case' than God's (so-called) primary causation. In fact, the use of the dream-dreamer and author-fiction relations to explain this contrast has precedent in the Jewish tradition (see Lebens 2015, forthcoming; Citron 2015). The comparison has also been employed by Thomists such as James Ross (1969, 255-258). However, considerable care must be exercised in interpreting the diminished reality thesis if one is to maintain classical theism. To hold that nothing but God strictly speaking exists would be to collapse into pantheism, and to deny causal efficacy to creatures would surely make God the

15. If logical and mathematical truths do not depend on History, a different account will be needed to explain the non-trivial truth of counterpossibles involving God's explicitly willing logical or mathematical propositions.

16. In Pearce, forthcoming(a), I further defend the claim that regarding God's will as grounding, rather than causing, its fulfillment is necessary for a satisfying account of omnipotence.

17. I thank Sandra Visser for emphasizing this point. 
author of sin. We must therefore carve out some space for the existence and causal efficacy of creatures. ${ }^{18}$

In plain language, we say that there is a fictional detective named 'Holmes', and there are several species of Star Trek aliens, and so forth. These are perfectly ordinary and perfectly literal uses of the existential 'is'. ${ }^{19}$ At the same time, however, we say that Sherlock Holmes is not a real detective, but rather a fictional character, and that we do not know whether there is really life on other planets. A satisfactory metaphysical picture should not only preserve the truth of these claims, but give some metaphysical weight to them. The objection that my model has the consequence that ordinary created objects are not real is best understood as claiming that the model undermines the metaphysical significance of the plain language distinction between real objects, on the one hand, and dream objects and fictional objects on the other.

This distinction is indeed elided when one attempts to accommodate the existence of fictional objects within the framework of a Quinean meta-ontology (as in van Inwagen 1977), for on such a view 'really' can only mean something like 'literally' or 'strictly speaking'. Accordingly, on this kind of view, fictional objects really exist, since quantification over fictional objects is ineliminable. ${ }^{20}$ One could escape this objection by adopting an ontology with two modes of existence, real and unreal, where unreal existence would be accorded not only to fictional objects, but also to dream objects, imaginary objects, posits of false scientific theories, and so forth. My model, however, suggests that we are related to God in something like the way fictional objects are related to us. It might be thought that we therefore fall on the unreal side of the distinction.

In fact, the grounding approach to ontology which is here presupposed provides a neat solution to these problems. The metaphysical significance of 'real' stems from its association with 'fundamental': the real objects are the fundamental objects. But fundamentality comes in degrees, with grounded entities being less fundamental than the entities that ground them. Accordingly, since dreams are grounded in dreamers, the dreamers are more fundamental than the dreams. It is in this sense that dreamers and the objects in their waking environs are real but dream objects are not. My model does not undermine the dependence of dreams on dreamers; it merely posits that the dreamers, in turn, depend on God. Accordingly, the ordinary distinction between real objects and dream objects is in no way undermined, for the real objects are more fundamental than the dream objects, and this is what we mean in calling them 'real'. ${ }^{21}$

18. A similar collection of difficulties for the dream model is discussed by Lebens 2015, $185-194$.

19. This claim is, admittedly, somewhat controversial, and there is not space to defend it here. For such defenses, see van Inwagen 1977; Thomasson 1999; Schnieder and Solodkoff 2009; Kripke 2013, 69-83. For an opposing view, see Everett 2005, 2007. For an overview of the debate about sentences that apparently quantify over fictional objects, see Friend 2007.

20. This is closely connected to the objection of Everett 2007 that such views cannot accommodate the truth of sentences such as 'Sherlock Holmes does not (really) exist,' which plain language takes to be true in many contexts.

21. In my view, fundamentality is actually only one of several criteria included in the plain 
So much for the existence of created objects. What of their causal efficacy? According to the model, the causal relations within History are the only genuine causal relations; there is not some more basic level of causation underlying History. There are, of course, dream causes and fictional causes and so forth, but the causal relations that make up History are the most real (i.e., most fundamental) causal relations there are. Foundational grounding is not (literally, univocally) causal, and so does not preempt creaturely causation.

Nevertheless, one might worry that, on this view, causation is not a genuine 'making it the case' relation: God's ultimate 'making it the case' preempts any creaturely activity. There are really three distinct objections in the neighborhood here. First, one might worry that the model leads to divine omnidetermination, and this kind of omnidetermination is inconsistent with genuine activity on the part of creatures, and especially human freedom. Second, one might worry that, on this view, creatures do not genuinely depend on their causes, since it is not the created cause but rather the will of God that made the creatures exist. Third, one might worry that on this view created causes can no longer serve as explanations, their explanatory force having been preempted by God.

To the first objection I respond that I have no particular commitment to avoiding omnidetermination since I find it far from obvious that omnidetermination is inconsistent with human freedom. Nevertheless, for those philosophers who do find omnidetermination problematic, there is a way of endorsing my model while avoiding omnidetermination. The objection assumes that, when two objects are related by constitution, the features of the constituted object are fully determined by the features of the constituting object. However, this assumption would be denied by various sorts of anti-reductionists. For instance one might suppose that a human organism constitutes a human person while holding that the human person has and exercises causal powers in a way that is not determined by the human organism. ${ }^{22}$ This approach to constitution would open up the possibility that History might be constituted by God's act of will without being determined by God in every respect. If more than one possible history could have been constituted by the very same divine creative act (or if History could have differed in certain ways without any difference in God's creative act), then standard theistic options for avoiding omnidetermination (simple foreknowledge, open theism, Molinism) are available. ${ }^{23}$

In response to the second objection, which claims that the model prevents

language notion of reality, but it is the criterion that is relevant to the present objection. The relative weight of the several criteria and the location of the 'cut-off' employed in drawing the binary real/unreal distinction vary contextually. For further development and defense of this approach to reality, see Pearce, forthcoming(c), $\S 1.3$.

The model does, of course, make created objects less fundamental than God and there is therefore a sense in which the model holds that, from God's perspective, created objects are not real (cf. Lebens, forthcoming). However, it is more accurate to say that ordinary created objects are more real than dream objects but less real than God. Reality and fundamentality come in degrees.

22. For anti-reductionist views similar (but not identical) to the one contemplated here, see Baker 2000; 2007, chs. 3-5; Merricks 2003.

23. An anonymous referee worries that if this route is taken then God will no longer provide 
created objects from depending on their created causes, note that, on my model, objects exhibit robust counterfactual dependence on their causes. Were it not for the causal chain leading up to the encounter of a certain sperm with a certain egg, I would not exist. Why not? Because my very being depends on (more specifically: is narratively grounded in) that causal sequence. It is, of course, a disputed matter exactly how much of an object's causal history is essential to it, but if created objects are narratively grounded in History which, recall, is the complete causal story of the world - then clearly they do depend counterfactually, and indeed metaphysically, on their causes.

In response to the third objection, that created causes do not, on this model, explain their effects, note that even in dreams and fictions there are causes, and these causes do explain their effects. Thus it is because Tybalt is stabbed by Romeo that Tybalt dies. Of course, it is also because Shakespeare wrote the play that way that Tybalt dies. The second explanation is more fundamental than the first, but it does not preempt the explanation in terms of fictional causes. Similarly, the constitution of History by God's act of will provides a more fundamental explanation than the causal explanation of a particular event, but it does not preempt the causal explanation.

\subsection{Foundational Grounding is Explanatory}

Having completed the exposition of my model of foundational grounding and defended its intelligibility, I now proceed to argue that the model is explanatory of History. I assume that there is such a thing as objective explanation and that it is a relation that obtains between true propositions or obtaining states of affairs (see Pruss 2006). Explanatoriness is a relation that obtains between a hypothesis and some data just in case if the hypothesis were true it would explain the data. Accordingly, my aim in this subsection is to argue that if the hypothesis God is the foundational ground of History were true it would explain the fact that History exists and is as it is.

I presuppose that grounding is intelligible. While some philosophers dispute this (e.g., Hofweber 2009, §2; Daly 2012), it is now widely held. Most defenses of the intelligibility of grounding proceed by pointing to our ordinary explanatory practices and, in particular, to plain language uses of 'because'. Thus Fabrice Correia gives the following examples of explanatory claims (Correia 2008, 1022): ${ }^{24}$

- The ham sandwich exists because the slice of ham is between the two pieces of bread;

- Sam is experiencing pain because his brain is in a physical state which is [here an appropriate description]; ${ }^{25}$

a complete explanation of History. However, many libertarians hold that an agent's action may have a complete explanation even though the agent could have done otherwise. See Pruss 2006 , ch. 7 .

24. Correia's term is 'ontological dependence,' but all of these examples can plausibly be regarded as instances of what I call 'grounding'.

25. Brackets original. 
- The event that was Sam's walking yesterday exists because Sam was walking yesterday;

- The redness of this apple exists because the apple is red;

- The set $\{$ Socrates $\}$ exists because Socrates does.

In the same way, on the model I have proposed, History exists and is as it is because God's act of will exists and is as it is, and God's act of will exists because God performs it.

Objections to the explanatoriness of my hypothesis, unless they are objections to the very notion of grounding, should therefore not be objections to its basic structure: if the notion of grounding has a place in philosophy at all, then grounding relations are explanatory. There are, however, three more serious objections. First, it may be thought that the model is too vague and schematic to be an explanation. Second, it may be thought that the explanation is objectionably ad hoc. Third, it may be thought that this model does not give us the "reason with which to stop" that Leibniz sought, and therefore does not make explanatory progress.

To the first objection I reply that in general vague and schematic explanations are explanations. It is true that we ought (ceteris paribus) to prefer explanations that are more precise and detailed. This, however, is not because vague explanations are not explanatory. It is because precision and detail are good-making features of explanations. So, for instance, the question 'why did Smith die?' can be answered, 'he died because of illness' or 'he died because he was murdered (by someone somehow for some reason)'. Both of these answers are vague and schematic. If we are engaged in an inference to the best explanation, then a more specific and detailed explanation is ceteris paribus preferable. Furthermore, it is difficult to determine which of two vague and schematic explanations is best without having recourse to more specific variants of them. So, for instance, if the hypothesis that Smith died due to illness is superior to the hypothesis that he was murdered, this will typically be because some specific illness hypothesis does a better job of explaining the data than any murder hypothesis does. This is not a difficulty about whether the hypotheses are explanatory; it is a difficulty about whether the hypothesis is the best explanation. However, even opponents of the Principle of Sufficient Reason generally admit that any 'non-disastrous' explanation is better than none (see Kleinschmidt 2013, 77). Thus, although a detailed and specific hypothesis is better than a vague and schematic one, and although it is difficult to compare vague and schematic hypotheses, it is nevertheless true that the vague and schematic hypothesis that God is the foundational ground of History may be accepted as the best explanation of History if no other explanation is available, or if it is all-things-considered superior to competing hypotheses (cf. O'Connor $2013, \S 4)$.

My reply to the second objection is the same as my reply to the first: ad hoc hypotheses are explanatory, but an ad hoc explanation is rarely the best explanation. Consider the ad hoc hypothesis that traffic lights change as they 
do because tiny gnomes run around in the mechanism flipping switches. If there really were such gnomes, then this would be a correct explanation. The problem with the gnome hypothesis is not that it is un-explanatory, but simply that there are other explanations available that explain just as much of the data and better accord with our overall picture of the world.

Whether (and to what degree) my model (or classical theism in general) should be regarded as ad hoc will therefore depend on how independently plausible one finds classical theism (and the other elements of the model), whether it turns out to be able to do other explanatory work elsewhere, whether there are other independent lines of evidence in its favor, and so forth. These issues cannot be addressed here, but these issues are relevant only to comparing competing explanations. Since (as I will soon argue) naturalism leaves the explanandum completely unexplained, these factors are not relevant to the present project.

Perhaps some will think that my model is ad hoc in a more specific way that prevents it from making explanatory progress. According to this third objection, because the posits of my model themselves stand in need of explanation, the inference to the best explanation is here unjustified.

This is a sensible thing to say about the gnome traffic light hypothesis: that there should be such gnomes is far more puzzling than that traffic lights should change. Hence if explanation is meant to involve the removal of puzzlement or mystery (Pruss 2006, 18, et passim), it would seem that the gnome hypothesis must be regarded as a failed explanation unless and until the gnomes are explained. Some might regard the existence of God as similarly puzzling or mysterious, so that overall puzzlement is not reduced by my model.

In response, consider three structures explanation might have. First, there may be an infinite chain of explanations, which never terminates at all. Second, the chain of explanations may terminate in brute facts. Brute facts are facts that stand in need of explanation, but nevertheless do not have explanations. Third, the chain of explanations may terminate in what Shamik Dasgupta calls 'autonomous facts' - facts for which it makes no sense to ask why (Dasgupta 2014b, 575-580; 2016, 383-387).

Consider the first case first. My model is consistent with the existence of an infinite chain of causal explanations, but claims that this infinite chain nevertheless itself has an explanation. The objection claims that the entity involved in that explanation (God) stands in need of further explanation. But if we are comfortable with infinite chains of explanation, this ought not to bother us. Instead, it ought to send us searching for the next link in the chain.

Now consider the second case. Intuitively, some brute facts are worse than others. Many physicalists think that taking as brute the initial configuration of the physical universe, together with the laws of nature, is more satisfying than taking as brute the existence of God and God's creative act (e.g., Oppy 2013, 55-56). Other philosophers regard the existence of God as a better candidate for a brute fact (e.g., Swinburne 1979, ch. 5; 1996, ch. 3). Although considerations of simplicity, systematicity, and so forth can be (and have been) brought to bear here, it seems likely that this debate will ultimately come to an unresolvable clash of intuitions. 
The third scenario would clearly be the most intellectually satisfying, if it could be made to work without unacceptable consequences. I will focus on this case, since it has been widely held within the tradition that classical theism does allow for the truth of the Principle of Sufficient Reason - understood here as the claim that everything that stands in need of explanation is in fact explainedwithout unacceptable consequences. I will argue that this traditional view is correct.

What sorts of facts might be autonomous? The most obvious candidates are the various sorts of definitions. Thus although the fact that the English word 'bachelor' means an unmarried male admits of a historical/etymological explanation, the fact that bachelors are unmarried males needs no explanation. If there are such things as Aristotelian 'real definitions' - definitions not of words but of things - then these are likewise good candidates for autonomous facts. Real definitions would be statements of essences, and they would not require further explanation (cf. Dasgupta 2014b, 577-580; 2016, 385-390).

On the model under discussion, the answer to the question, 'why is History occurring the way it is?' is 'because God so willed.' Although this may sound like a causal explanation, it is not, since God's act of willing does not cause, but rather constitutes, History. The next question we can ask is, "why did God so will?' Here, of course, we fall upon the thorny problem of the explanation of free actions, but we may assume that God's free act of willing is explained in whatever way free acts are generally explained. ${ }^{26}$ We may then go on to ask, why is it that God existed and was free so to will? Merely asserting that this is true necessarily does not give us a 'reason with which to stop', for necessary truths can and often do have explanations. A more subtle strategy is needed.

According to Thomas Aquinas, "the proposition, 'God exists,' of itself is selfevident ... [but] because we do not know the essence of God, the proposition is not self-evident to us" (Aquinas Summa Theologica, Iq2a1). The idea here is that the real definition of God is unknown to us, but a being who knew it would be in a position to demonstrate God's existence a priori (see Forgie 1995). If this were true of God, then the fact that God exists and is free would either itself be autonomous (as part of the real definition of God), or would be explained by the autonomous fact that God's essence is as it is.

If this strategy is correct, then there is a sound modal ontological argument. To construct this argument, we stipulate that the word 'God' shall stand for the (unknown) real definition of God. We then assert that God's existence is possible, and that God exists necessarily if at all. God is therefore necessary, and therefore actual. On the view described, the premises of this argument would follow directly from the divine essence, and the fact that the divine essence is as it is would be autonomous.

This strategy does not, however, make the argument from contingency de-

26. In my view, any version of libertarianism that holds that free actions cannot be explained succumbs to the randomness objection (the event is not an action of yours unless you appear in the right sort of way in an explanation of its occurrence), but there is not space here to defend that claim. For a discussion of various ways in which libertarians might allow that free actions can be explained, see Pruss 2006, ch. 7 . 
pend on the ontological argument. On the contrary, the ontological argument depends on the argument from contingency: after we have posited God in order to explain History, we see that our explanation can bottom out in autonomous facts, and therefore give us a maximally satisfying explanatory structure, only if the real definition of God has certain features. This gives us reason to hypothesize that the real definition of God does have these features, i.e., that there is a sound ontological argument. Because we do not have independent grounds for believing the premises of this ontological argument, we cannot use it to establish the existence of God. This does not, however, prevent us from using it to explain God's existence and, indeed, God's necessary existence.

Having explained why God exists and is free, we can go on to explain God's free act in (something like) the usual way in which free acts are explained (whatever that is). This act in turn explains History — not by causing it, but by constituting it. In this way, explanation bottoms out in the definition of God.

This additional stage of explanation - the explanation of why God exists and is free - is vague and schematic like the earlier stage, insofar as we don't actually know the real definition of God which is employed in our modal ontological argument. Nevertheless, the schema is a satisfying one which, unlike naturalism, posits no brute facts.

\section{$3 \quad$ Naturalism Leaves History Unexplained}

Naturalism, as I use the term here, is the view that any metaphysics that goes beyond natural science ought to be rejected. In this section, I argue that History cannot be explained within the boundaries of this view.

Although most naturalist philosophers simply accept that their view requires them to posit brute facts, and would no doubt include the occurrence of History among these facts (see, e.g., Grünbaum 2004; Fahrbach 2005), some have attempted to accommodate ultimate explanation within naturalistic boundaries. The reason these attempts fail is simple. As long as we stay within the bounds of (current) natural science, the only available variety of non-necessitating explanation is indeterministic causation. However, on pain of circularity, no causal explanation of History can be given. Therefore, naturalistic explanations of History will be necessitating explanations. But to give a necessitating explanation of History is to restrict the scope of possibility in a way that is at odds with current science and hence cannot be accepted by the naturalist.

To see how this problem arises, we will consider two recent attempts at ultimate naturalistic explanation. The first, due to Shamik Dasgupta, argues that essentialist explanation is a scientifically accredited variety of explanation, and that there is some entity (or there are some entities) known to science whose existence can be given essentialist (rather than causal) explanations. The second, due to Marc Lange, argues that the laws of nature non-causally explain certain facts, and that among these may be some existence facts. ${ }^{27}$

27. If, as some philosophers suppose (e.g., Bird 2005; Yates 2013), laws of nature are grounded in essences, these proposals may be equivalent. 
Dasgupta defends a Principle of Sufficient Reason according to which every fact that stands in need of an explanation has one. He concedes (at least for the sake of argument) that existence facts, if they are to be explained at all, must be explained in terms of other existence facts. These two claims, together with the rejection of explanatory circles and regresses, entail that not all existence facts stand in need of explanation (Dasgupta 2016, 397). Given Dasgupta's view, discussed above, that the autonomous facts are essentialist facts (real definitions), this implies the existence of one or more beings whose essence includes existence, as was traditionally said of God.

Despite this consequence, Dasgupta denies that his theory is anti-naturalistic. ${ }^{28}$ He suggests that our best scientific theories might in fact be committed to entities whose essence includes existence. If there is just one such entity, then Dasgupta's model will look quite similar to mine, simply substituting some entity known to science into the place of God. If, however, there is a plurality of such entities, then the structure will be somewhat different.

Dasgupta suggests spacetime as a candidate for a unique essentially existing entity. On this view,

at rock bottom there is some kind of physical "space" (in the broad sense of the term) in whose nature it is to exist and instantiate some kind of structure ... The view will then be that all other (substantive) facts - about my armchair, my mental states, my duties and obligations - are grounded in the existence and structure of that underlying physical space (398).

Let us grant the plausible, but not uncontroversial, assumption that spacetime in modern physics should be given a substantivalist interpretation, so that spacetime is a naturalistically respectable entity. ${ }^{29}$ Granting this assumption, the first problem with Dasgupta's approach is that, according to straightforward interpretations of General Relativity, the geometric structure of our spacetime is physically contingent. There are many global solutions to Einstein's Field Equations, and it is part of the practice of physics to distinguish among those solutions that are and are not 'physical' (or, as philosophers would say, physically possible). ${ }^{30}$ Many different solutions are regarded as 'physical,' and these correspond to different possibilities for the global structure of spacetime. However, if it is in the essence of spacetime to exist and have the structure it does, then no alternative structures are possible. Consistency with actual physics requires either that our spacetime exist only contingently (so that a different spacetime with an alternative structure might have existed) or that our spacetime has its geometric structure only contingently.

28. Dasgupta considers the claim that his theory has anti-naturalistic consequences as an objection that may be raised against his theory but does not explicitly endorse naturalism himself.

29. For a carefully nuanced discussion of the extent to which modern physics supports substantivalism, see Maudlin 1993. Dasgupta 2011 attacks standard substantivalist interpretations of General Relativity and proposes a non-standard version of substantivalism.

30. For accounts of some historical disputes about which solutions are physical, see Earman 1995, ch. 1; Singh 2004, 151-155. 
Let us suppose, then, that spacetime exists essentially, but has its geometric structure accidentally (and so, in some sense, contingently). ${ }^{31}$ If this is to explain History, presumably it will do so by grounding the existence of the entities (or states) within History, including the causal powers of these entities, which will then give rise to the sequence of causes and effects. ${ }^{32}$

Although this approach may, in a certain sense, provide an explanation of History, by holding that History is constituted by certain features of spacetime, it cannot provide the kind of explanation Leibniz demanded, an explanation of "why the thing is as it is and not otherwise" (Leibniz [1714] 1969, §7). This is because, as has been observed, the global structure of spacetime is physically and hence metaphysically - contingent. Thus the global structure of spacetime cannot follow from the essence of spacetime. Yet this global structure will, on this view, be (directly or indirectly) responsible for History having the structure it does. Furthermore, on this sort of view, the global structure of spacetime cannot, on pain of circularity, be directly or indirectly explained in terms of any of the events in History - which is to say, it cannot be explained causally. This is again inconsistent with straightforward interpretations of General Relativity, since that theory is usually understood to say that the shape of spacetime can be explained (perhaps causally) in terms of the distribution of mass-energy. ${ }^{33}$

I argued above that an explanation should not be regarded as a failure simply because the explanans requires further explanation. In this case, however, naturalism renders the explanans (the global structure of spacetime) in principle inexplicable, since the proposal under consideration rules out both essentialist explanations and causal explanations, and no other scientifically accredited sorts of explanation have been identified. Accordingly, even if this is to be regarded as a successful explanation of History, we could just run the argument from contingency again by demanding an explanation of the global structure of spacetime. This contrasts with the theistic model I have proposed, where contingency is introduced in a non-causal, but intelligible, way by God's choice.

On Marc Lange's alternative proposal, the laws of nature provide non-causal explanations of certain facts. The laws, Lange says, may entail certain propositions without saying that anything causes them. Lange makes no concrete proposals about what such a proposition might be in modern physics, but he suggests that Newton may have been correct in holding that his physics entailed the existence of space and time (Lange 2013, 244).

The idea of interest for our purposes is that the laws of physics may somehow entail, and thereby explain, the global structure of History. This proposal, however, runs into the same difficulty as Dasgupta's: the global causal structure is not physically necessary. Both proposals turn out to be revisionary with respect to physics.

The general problem is this: current physics knows only one way of selecting

31. Dasgupta allows for contingency only in a relatively weak sense, but admits that the essentialist facts are not contingent in any sense.

32. A theory of this sort is developed in detail by Schaffer 2009b.

33. "Matter and energy, like the sun, cause space (and spacetime) to warp and curve" (Greene 2005, 69, emphasis added). 
between multiple, genuinely possible outcomes, and this is by indeterministic causation. But History cannot be explained causally. Other naturalistically respectable patterns of explanation render the explanandum (at least) physically necessary. But the global structure of History is not physically necessary. ${ }^{34}$ Accordingly, no naturalistic explanation of History is possible.

\section{Conclusion}

The cosmological argument from contingency can be understood as a demand for an explanation of History, the total sequence of causes and effects in the universe. Such an event, however, cannot, on pain of circularity, have a causal explanation. A non-causal explanation of History is possible given classical theism but impossible given naturalism. Accordingly, the argument from contingency succeeds in providing excellent reason for favoring theism over naturalism. Of course, this reason will be decisive only if a sufficiently strong Principle of Sufficient Reason is endorsed and I have given no argument in favor of such a principle. If the Principle of Sufficient Reason is rejected, a more holistic comparison of theories will be necessary. Additionally, naturalism and classical theism are not the only perspectives to be considered and there are many possible classical theistic models besides the one here proposed. Thus considerable work remains to be done if it is to be shown that my classical theistic model is in fact the best explanation of History. Nevertheless, the fact that such a model exists shows that theism has a substantial explanatory advantage over naturalism, and this result is quite significant enough. ${ }^{35}$

\section{References}

Adams, Robert Merrihew. 1983. "Divine Necessity." Journal of Philosophy 80 (11): 741-752.

Aquinas, St. Thomas. 1920. The Summa Theologica of St. Thomas Aquinas. 2nd ed. Translated by Fathers of the English Dominican Province. London: Burns Oates \& Washbourne.

Audi, Paul. 2012. "A Clarification and Defense of the Notion of Grounding." In Correia and Schnieder 2012, 101-121.

34. In $\S 1$, I said that the naturalist was free to accept a necessary initial state of the universe. This open possibility is significantly weaker than the claim here rejected, that the global structure of History and/or spacetime might be necessary.

35. This paper benefited from the comments of two anonymous referees and from discussions with Sandra Visser, Kenneth Silver, Joshua Rasmussen, Alexander Pruss, Samuel Lebens, and the participants at the 2015 St. Thomas Summer Seminar in Philosophy of Religion and Philosophical Theology, especially Bob Hartman, Blake McAllister, Michael Rota, and Dean Zimmerman. 
Baker, Lynne Rudder. 2000. Persons and Bodies: A Constitution View. Cambridge Studies in Philosophy. Cambridge: Cambridge University Press.

. 2007. The Metaphysics of Everyday Life. Cambridge: Cambridge University Press.

Bennett, Karen. 2011. "Construction Area (No Hard Hat Required)." Philosophical Studies 154 (1): 79-104.

Bird, Alexander. 2005. "Laws and Essences." Ratio 18 (4): 437-461.

Bonhoeffer, Dietrich. 1997. Creation and Fall. Edited by John W. de Gruchy. Translated by Douglas Stephen Bax. Vol. 3. Dietrich Bonhoeffer Works. Minneapolis: Fortress Press.

Campbell, Joseph K. 1996. "Hume's Refutation of the Cosmological Argument." International Journal for Philosophy of Religion 40 (3): 159-173.

Chalmers, David J., David Manley, and Ryan Wasserman, eds. 2009. Metametaphysics: New Essays on the Foundations of Ontology. Oxford: Clarendon Press.

Citron, Gabriel. 2015. "Dreams, Nightmares, and a Defense Against Arguments From Evil." Faith and Philosophy 32 (3): 247-270.

Correia, Fabrice. 2008. "Ontological Dependence." Philosophy Compass 3 (5): 1013-1032.

Correia, Fabrice, and Benjamin Schnieder, eds. 2012. Metaphysical Grounding: Understanding the Structure of Reality. Cambridge: Cambridge University Press.

Craig, William Lane. 1979. The Kalam Cosmological Argument. New York: Barnes \& Noble Books.

Daly, Chris. 2012. "Scepticism about Grounding." In Correia and Schnieder 2012, 81-100.

Dasgupta, Shamik. 2011. "The Bare Necessities." Philosophical Perspectives 25 (1): 115-160.

- 2014a. "On the Plurality of Grounds." Philosophers' Imprint 14 (20).

. 2014b. "The Possibility of Physicalism." Journal of Philosophy 111 (9/10): $557-592$.

—. 2016. "Metaphysical Rationalism." Noûs 50 (2): 379-418.

Earman, John. 1995. Bangs, Crunches, Whimpers, and Shrieks: Singularities and Acausalities in Relativistic Spacetimes. New York: Oxford University Press.

Everett, Anthony. 2005. "Against Fictional Realism." Journal of Philosophy 102 (12): 624-649. 
Everett, Anthony. 2007. "Pretense, Existence, and Fictional Objects." Philosophy and Phenomenological Research 74 (1): 56-80.

Fahrbach, Ludwig. 2005. "Understanding Brute Facts." Synthese 145 (3): 449466.

Fine, Kit. 2012. "Guide to Ground." In Correia and Schnieder 2012, 37-80.

Forgie, J. William. 1995. "The Cosmological and Ontological Arguments: How Saint Thomas Solved the Kantian Problem." Religious Studies 31 (1): 89100.

Friend, Stacie. 2007. "Fictional Characters." Philosophy Compass 2 (2): 141156.

Gale, Richard M., and Alexander R. Pruss. 1999. "A New Cosmological Argument." Religious Studies 35 (4): 461-476.

Goldschmidt, Tyron, ed. 2013. The Puzzle of Existence: Why Is there Something Rather Than Nothing? New York: Routledge.

Goldschmidt, Tyron, and Kenneth L. Pearce, eds. Forthcoming. Idealism: New Essays in Metaphysics. Oxford: Oxford University Press.

Greene, Brian. 2005. The Fabric of the Cosmos: Space, Time, and the Texture of Reality. New York: Vintage Books.

Grünbaum, Adolf. 2004. "The Poverty of Theistic Cosmology." British Journal for the Philosophy of Science 55 (4): 561-614.

Hocutt, Max. 1974. "Aristotle's Four Becauses." Philosophy 49:385-399.

Hofweber, Thomas. 2009. "Ambitious, Yet Modest, Metaphysics." In Chalmers, Manley, and Wasserman 2009, 260-289.

Kant, Immanuel. (1781) 1998. Critique of Pure Reason. Edited and translated by Paul Guyer and Allen W. Wood. The Cambridge Edition of the Works of Immanuel Kant. Cambridge: Cambridge University Press.

Kleinschmidt, Shieva. 2013. "Reasoning Without the Principle of Sufficient Reason." In Goldschmidt 2013, 64-79.

Koons, Robert C. 1997. "A New Look at the Cosmological Argument." American Philosophical Quarterly 34 (2): 193-211.

— 2008. "Epistemological Foundations for the Cosmological Argument." Oxford Studies in Philosophy of Religion 1:105-133.

Kripke, Saul A. 2013. Reference and Existence: The John Locke Lectures. New York: Oxford University Press.

Lange, Marc. 2013. "Are Some Things Naturally Necessary?" In Goldschmidt 2013, 235-251. 
Lebens, Samuel. 2015. "God and His Imaginary Friends: A Hassidic Metaphysics." Religious Studies 51 (2): 183-204.

. Forthcoming. "Hassidic Idealism: Kurt Vonnegut and the Creator of the Universe." In Goldschmidt and Pearce, forthcoming.

Leibniz, Gottfried Wilhelm. (1697) 1969. "On the Radical Origination of Things." In Leibniz 1969, 486-491.

. (1714) 1969. "The Principles of Nature and Grace, Based on Reason." In Leibniz 1969, 636-642.

. 1969. Philosophical Papers and Letters. 2nd ed. Edited and translated by Leroy E. Loemker. Dordrecht: Kluwer Academic Publishers.

Malebranche, Nicolas. (1674-1675) 1997. The Search after Truth. Edited and translated by Thomas M. Lennon and Paul J. Olscamp. Cambridge Texts in the History of Philosophy. Cambridge: Cambridge University Press.

Maudlin, Tim. 1993. "Buckets of Water and Waves of Space: Why Spacetime is Probably a Substance." Philosophy of Science 60 (2): 183-203.

Merricks, Trenton. 2003. Objects and Persons. Oxford: Clarendon Press.

O'Connor, Timothy. 2008. Theism and Ultimate Explanation: The Necessary Shape of Contingency. Malden, MA: Blackwell.

— 2013. "Could There Be a Complete Explanation of Everything?" In Goldschmidt 2013, 22-45.

Oppy, Graham. 2009. "Cosmological Arguments." Noûs 43 (1): 31-48.

—. 2013. "Ultimate Naturalistic Causal Explanations." In Goldschmidt 2013, 46-63.

Pearce, Kenneth L. 2016. "Counteressential Conditionals." Thought: A Journal of Philosophy 5 (1): 73-81.

Forthcoming(a). "Counterpossible Dependence and the Efficacy of the Divine Will." Faith and Philosophy.

Forthcoming(b). "Infinite Power and Finite Powers." In The Infinity of God: Scientific, Theological, and Philosophical Perspectives, edited by Benedikt Paul Göcke and Christian Tapp. Notre Dame University Press.

Forthcoming(c). "Mereological Idealism." In Goldschmidt and Pearce, forthcoming.

Pearce, Kenneth L., and Alexander R. Pruss. 2012. "Understanding Omnipotence." Religious Studies 48 (3): 403-414.

Pereboom, Derk. 2011. Consciousness and the Prospects for Physicalism. New York: Oxford University Press. 
Proops, Ian. 2014. "Kant on the Cosmological Argument." Philosophers' Imprint 14 (12): 1-21.

Pruss, Alexander R. 2004. "A Restricted Principle of Sufficient Reason and the Cosmological Argument." Religious Studies 40 (2): 165-179.

- 2006. The Principle of Sufficient Reason: A Reassessment. Cambridge Studies in Philosophy. Cambridge: Cambridge University Press.

- 2011. Actuality, Possibility, and Worlds. Continuum Studies in Philosophy of Religion. New York: Continuum.

Ross, James F. 1969. Philosophical Theology. Indianapolis: Bobbs-Merrill.

Schaffer, Jonathan. 2009a. "On What Grounds What." In Chalmers, Manley, and Wasserman 2009, 347-383.

2009b. "Spacetime the One Substance." Philosophical Studies 145 (1): $131-148$.

- 2012. "Grounding, Transitivity, and Contrastivity." In Correia and Schnieder 2012, 122-138.

Schnieder, Benjamin, and Tatjana von Solodkoff. 2009. "In Defence of Fictional Realism." Philosophical Quarterly 59 (234): 138-149.

Singh, Simon. 2004. Big Bang: The Origin of the Universe. Fourth Estate.

Smith, Donald P. 2003. "Kant on the Dependency of the Cosmological Argument on the Ontological Argument." European Journal of Philosophy 11 (2): 206218.

Swinburne, Richard. 1979. The Existence of God. Oxford: Clarendon Press.

- 1996. Is There a God? New York: Oxford University Press.

Thomasson, Amie L. 1999. Fiction and Metaphysics. Cambridge Studies in Philosophy. Cambridge: Cambridge University Press.

Vallicella, William F. 2000. "Does the Cosmological Argument Depend on the Ontological?" Faith and Philosophy 17 (4): 441-458.

van Inwagen, Peter. 1977. "Creatures of Fiction." American Philosophical Quarterly 14 (4): 299-308.

- 1990. Material Beings. Ithaca, NY: Cornell University Press.

Yates, David. 2013. "The Essence of Dispositional Essentialism." Philosophy and Phenomenological Research 87 (1): 93-128. 